\title{
Small Noncoding RNAs in the Germline
}

\author{
Jonathan P. Saxe and Haifan Lin \\ Yale Stem Cell Center and Department of Cell Biology, Yale University School of Medicine, New Haven, \\ Connecticut 06511 \\ Correspondence: haifan.lin@yale.edu
}

Small noncoding RNAs have emerged as potent regulators of gene expression, especially in the germline. We review the biogenesis and regulatory function of three major small noncoding RNA pathways in the germline: The small interfering RNA (siRNA) pathway that leads to the degradation of target mRNAs, the microRNA (miRNA) pathway that mostly represses the translation of target mRNAs, and the newly discovered Piwi-interacting RNA (piRNA) pathway that appears to have diverse functions in epigenetic programming, transposon silencing, and the regulation of mRNA translation and stability. The siRNA and miRNA pathways are present in the germline as well as many somatic tissues, whereas the piRNA pathway is predominantly confined to the germline. Investigation of the three small RNA pathways has started to reveal a new dimension of gene regulation with defining roles in germline specification and development.

I is an emerging theme among diverse higher eukaryotes that a large portion of the genome is actively transcribed. Many of these transcripts, however, do not encode proteins, and are thus called "noncoding RNAs (ncRNAs)." Noncoding RNAs range in size from 19-21 base pairs (bp) up to tens of kilobases in length and play crucial roles in organismal development. The regulatory role of noncoding RNAs is especially prominent within the germline, where they are required for mRNA splicing (snRNPs), protein synthesis (tRNAs and ribosomal RNAs), RNA maturation and modification (snoRNAs), maintenance of telomere ends (terc), and epigenetic regulation of chromosomes such as $\mathrm{X}$ inactivation (long noncoding RNAs).

Among ncRNAs, there are three major types of small ncRNAs: small interfering RNAs
(siRNAs, 21-23 bp), microRNAs (miRNAs, 21-23 bp), and the germline-enriched piwiinteracting RNAs (piRNAs, mostly 24-34 bp). A common characteristic of these ncRNAs is that they bind to proteins of the Piwi/ Argonaute family. These proteins are evolutionarily conserved, and characterized by the presence of the PAZ (Piwi-Argonaute-Zwille) and PIWI domains that are essential for their function. This family can be subdivided into two distinct subfamilies: The Argonaute (Ago) subfamily, which bind siRNAs and miRNAs and are ubiquitously present in somatic and germline cells, and the Piwi subfamily that binds piRNAs and is highly enriched in the germline. Here, we review small noncoding RNAs, with an emphasis on germline-enriched piRNAs.

Editors: Paolo Sassone-Corsi, Margaret T. Fuller, and Robert Braun

Additional Perspectives on Germ Cells available at www.cshperspectives.org

Copyright (C) 2011 Cold Spring Harbor Laboratory Press; all rights reserved; doi: 10.1101/cshperspect.a002717

Cite this article as Cold Spring Harb Perspect Biol 2011;3:a002717 
J.P. Saxe and H. Lin

\section{AN OVERVIEW OF THE ARGONAUTE/PIWI PROTEIN FAMILY}

Ago proteins are broadly expressed in most eukaryotes, whereas Piwi proteins are found only in sexually reproducing organisms, namely animals and ciliates (Fig. 1) (Beyret and Lin 2008). Ago/Piwi proteins contain a central PAZ domain of 100 residues that forms a pocket to bind the $3^{\prime}$ end of small RNAs. Mutational analysis of this domain, however, has suggested that it is not critical for RNA binding, which is instead mediated by the Piwi domain (Wang et al. 2008). The Piwi domain is a 350-residue carboxy-terminal domain involved in RNA binding and slicing. Site-directed mutagenesis has highlighted several critical residues that bind RNA using a combination of hydrogen bonding and base-pair stacking. The Piwi domain lies to one side of the ribonucleic acid complex to cut RNA bound within the domain (Song et al. 2004). Consistently, many Ago and Piwi proteins have been shown to possess slicing activity.

\section{THE siRNA AND miRNA PATHWAYS}

\section{Characterization and Functions of siRNAs}

RNA interference (RNAi), or posttranscriptional gene silencing (PTGS), has been characterized in many species. It was first observed in animals in Caenorhabditis elegans (Fire et al. 1998), in which endogenous transcripts could be effectively degraded by feeding worms with sequence-specific double-stranded RNA (dsRNA) (Fire et al. 1998). Sequence-specific degradation was also observed in Drosophila embryo extracts (Tuschl et al. 1999) and requires processing of dsRNA strands into 1921-bp siRNA duplexes (Zamore et al. 2000; Elbashir et al. 2001b). Nearly identical processing occurs in mammalian cells (Billy et al. 2001; Elbashir et al. 2001a). The RNAse III-like enzyme Dicer produces siRNAs from dsRNAs in worms (Grishok et al. 2001), flies (Bernstein et al. 2001; Hutvagner et al. 2001), and mammals (Bernstein et al. 2001; Billy et al. 2001), which are then integrated into Ago2-containing silencing complexes that mediate degradation of complementary transcripts. The biogenesis and function of the siRNA pathway is summarized in Figure 2A. This selective degradation of specific RNA messages defends against viral infection, represses transposition, and regulates endogenous gene expression.

Eight recent simultaneous reports detailed a novel class of siRNAs, termed endogenous siRNAs (endo-siRNAs), in Drosophila embryos and mouse oocytes. Drosophila endo-siRNAs are $21 \mathrm{bp}$ in length, exhibit little strand or
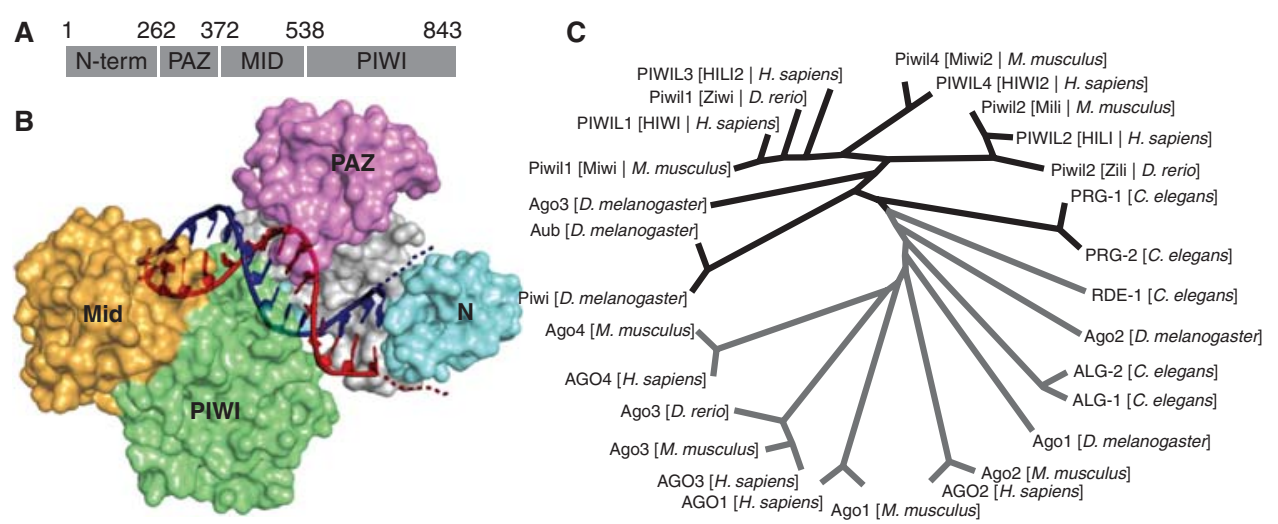

Figure 1. The PIWI/Ago family of proteins. (A) Schematic representation of the amino-terminal (N-term), PAZ, Mid, and PIWI domains of Drosophila Piwi. (B) Crystal structure of Thermus thermophilus Ago bound to a 21-bp guide RNA (red) and a 19-bp target RNA (blue). Figure created from data from Wang et al. (2009). (C) Radial cladogram of the Piwi (black branches) and Ago (gray branches) subfamilies. Human, mouse, zebrafish, and selected Caenorhabditis elegans Piwi and Ago proteins are shown. 

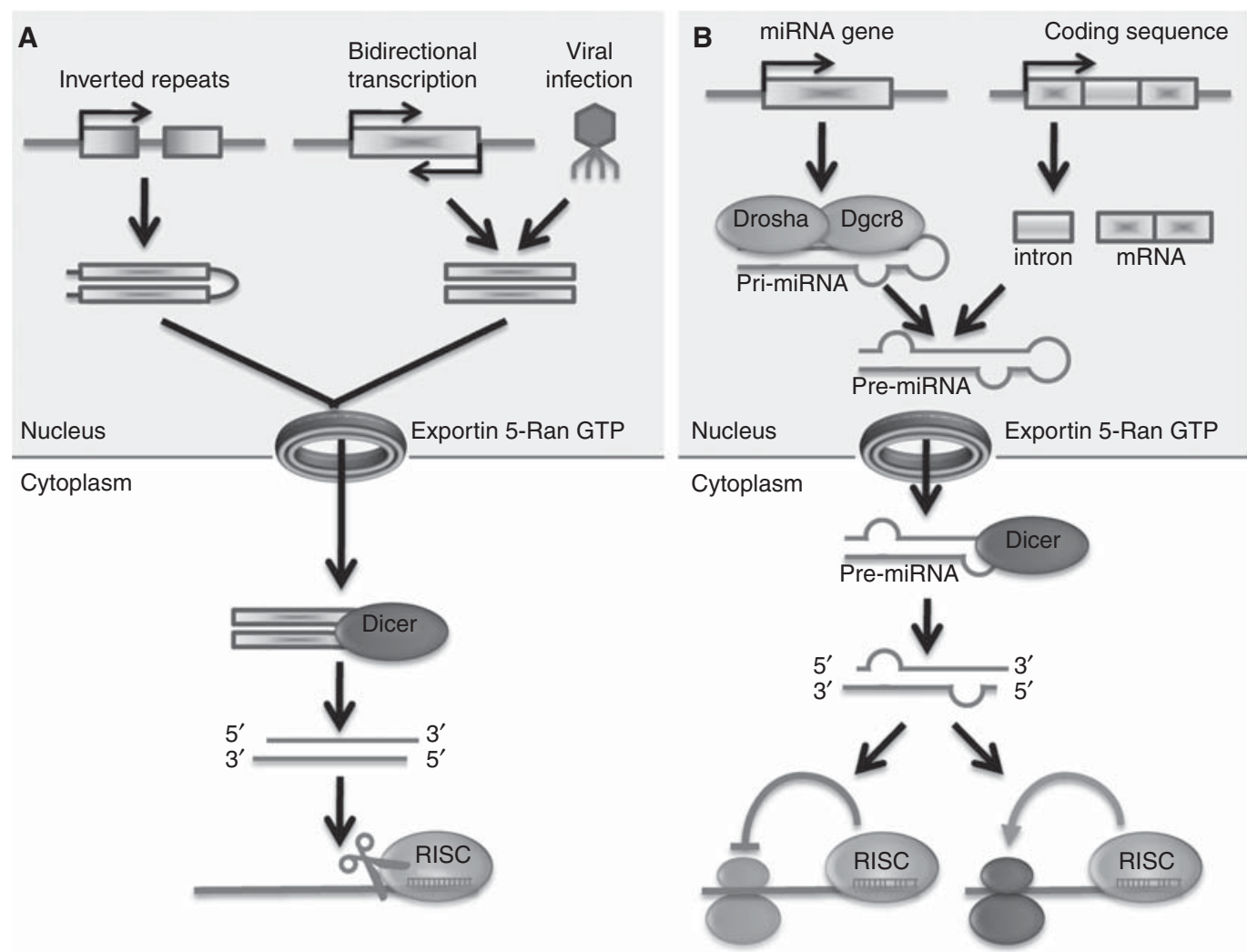

Figure 2. The siRNA and miRNA pathways. (A) Endogenous siRNAs are produced from inverted repeats or bidirectional transcription. The long dsRNA precursors are transported into the cytoplasm by Exportin5. Exogenous siRNAs are introduced by viral infection or transfection and are localized to the cytoplasm. In both cases, long dsRNAs are processed by Dicer to form mature siRNAs that are then incorporated into RNA-induced silencing complexes (RISCs) which mediate target cleavage. (B) miRNAs are produced by transcription of pri-miRNA precursors from miRNA genes, which are processed to pre-miRNAs by the microprocessor containing Drosha and Dgcr8. Alternatively, pre-miRNAs are also produced by splicing of intronic sequences containing miRNA sequences. Pre-miRNAs are exported from the nucleus by Exportin and processed into mature miRNAs by Dicer. miRNAs are then incorporated into RISCs that can mediate translational silencing or activation.

sequence bias, and arise mainly from repetitive genomic loci, suggesting a role for endo-siRNAs in defense against transposons. Consistently, there is a large increase in the activity of a subset of transposable elements in ago2 and dicer2 null flies (Chung et al. 2008; Czech et al. 2008; Ghildiyal et al. 2008; Kawamura et al. 2008; Okamura et al. 2008a,b). Profiling the small RNA population of mouse oocytes identified a large population of functional endo-siRNAs corresponding to transposon sequences, suggesting a conserved role for this pathway in genome defense (Golden et al. 2008; Tam et al. 2008; Watanabe et al. 2008).

\section{Characterization and Function of miRNAs}

miRNAs are produced through two distinct mechanisms (Fig. 2B). First, miRNAs are derived from primary transcripts, termed primiRNAs. Pri-miRNA genes are frequently arranged in tandem and several mature miRNAs can be derived from a single pri-miRNA. PrimiRNAs are processed by a protein complex 
containing Drosha and DGCR8 to form premiRNAs of $\sim 70-100$ base pairs in length. Pre-miRNAs adopt a hairpin structure and are exported from the nucleus via exportin 5 and Ran GTPase (Kim et al. 2009). Second, "mirtrons," miRNA sequences contained within introns of coding sequences, are released by spliceosome activity rather than Drosha cleavage and then fall into the miRNA pathway (Okamura et al. 2007; Ruby et al. 2007).

Once in the cytoplasm, Dicer generates mature miRNAs from pre-miRNAs. Mature miRNAs are 19-23-bp RNA duplexes containing a two-nucleotide $3^{\prime}$ overhang. Although either strand is capable of mediating translational silencing, only the strand whose $5^{\prime}$ end is more loosely bound to its complement is then incorporated into RNA-induced silencing complexes (RISCs) (Elbashir et al. 2001c; Martinez et al. 2002; Schwarz et al. 2003).

miRNAs generally regulate their targets through translational repression. The first two known RNAs, let-7 and let-4, were identified in genetic screens for heterochronic genes in C. elegans. These two genes produce short, $\sim 22$-nt transcripts with no protein-coding potential and bind to $3^{\prime}$ UTRs of specific mRNAs, inhibiting their translation into protein. Additional miRNAs were soon discovered in C. elegans (Lau et al. 2001; Lee and Ambros 2001), Drosophila, and human cell lines (LagosQuintana et al. 2001). To date, more than 600 miRNAs have been identified in mice and humans (miRBase http://microrna.sanger.ac. uk/cgi-bin/sequences/browse.pl. Sanger Institute Wellcome Trust).

miRNAs function in a variety of developmental, physiological, and pathophysiological processes. Single miRNAs can direct hematopoetic and neural stem/progenitor cells toward a specific cell fate (Chen et al. 2004; Cheng et al. 2009) and maintain pluripotency of embryonic stem cells (for review see Gangaraju and Lin 2009). miRNAs often display exquisite developmental, temporal, and tissue-specific expression, to the extent that it is now possible to accurately classify human cancers on the basis of their miRNA expression ( $\mathrm{Lu}$ et al. 2005). This powerful diagnostic approach could prove to be extremely useful in cancer therapy.

Germline Functions of the siRNA and miRNA Pathways

siRNA and miRNA pathway components have important functions in the germline. In Drosophila, maternal Dicer1 is required for the establishment of primordial germ cells (PGCs) (Megosh et al. 2006). Impairment of miRNA biogenesis by deletion of Dicer 1 or Loquacious results in defects in maintenance of germline stem cells (GSCs) (Forstemann et al. 2005; Park et al. 2007); clonal analysis showed that this was a cell-autonomous defect in GSC proliferation (Hatfield et al. 2005). This function is evolutionarily conserved, as mutations in Dicer1 in C. elegans likewise results in defects in germline formation and sterility (Knight and Bass 2001). Further studies have highlighted roles for specific miRNAs in these processes in Drosophila (Iovino et al. 2009; Yang et al. 2009).

Small RNAs are crucial to ensuring genomic integrity in the germline. Endo-siRNAs play critical roles in genome surveillance to keep transposons in check within the female germline, ensuring that they are degraded in an Ago2- and Dicer2-dependent manner (Czech et al. 2008). Indeed, recent studies have highlighted the predominance of endo-siRNAs, rather than miRNAs, as the key class of small ncRNAs in oocytes (Suh et al. 2010). A distinct small RNA pathway, utilizing the Piwi subfamily of the Argonaute/Piwi family of proteins, is also necessary for maintaining genomic integrity.

\section{PIWI PROTEINS AND piRNAs}

The Piwi subfamily of proteins functions specifically within the germline. Drosophila PIWI, the founding member the PIWI/AGO family, was discovered in a p-element insertion screen for genes that disrupt GSC function (Lin and Spradling 1997). Piwi mutant flies are sterile (Cox et al. 1998) because of defects in selfrenewal of GSCs (Cox et al. 1998, 2000). 


\section{Germline Functions of PIWI Proteins}

PIWI proteins are mainly expressed in the germline, although several somatic functions have been determined. Within the germline, PIWI proteins are involved in germline determination and gametogenesis.

\section{Formation of the Germline}

In Drosophila, loss of maternal piwi transcript results in loss of PGC formation. Furthermore, overexpression of increasing amounts of maternal piwi leads to a linear increase in the number of new PCGs formed (Megosh et al. 2006). Piwi interacts with the miRNA pathway components Dicer1 and Fmrp (Megosh et al. 2006) which play key roles in PGC specification, implying that Piwi could act to control miRNA-mediated mechanisms of PGC formation.

\section{The Male Germline}

Drosophila Piwi proteins function within the male germline. Piwi was discovered in a screen for mutants that disrupt GSC self-renewal in the testis. The Piwi GSC phenotype can be enhanced and suppressed by different haploinsufficient mutations, suggesting a dose-dependent effect of piwi in regulating GSC function (Smulders-Srinivasan and Lin 2003). The Drosophila Piwi protein Ago3 is also required for GSC maintenance, as male 5-7-day-old flies do not contain Vasa-positive germ cells adjacent to the somatic hub cells ( $\mathrm{Li}$ et al. 2009).

Mice have three Piwi homologs: Miwi, Mili, and Miwi2, which are all required for male fertility. Mili is expressed in PGCs at approximately embryonic day 12.5 (E12.5) of development and in postnatal GSCs, spermatogonia, spermatocytes, and round spermatids (Kuramochi-Miyagawa et al. 2004; Wang et al. 2009). Miwi is expressed in postnatal late primary spermatocytes through elongating spermatids (Deng and Lin 2002). In contrast, Miwi2 is expressed in gonocytes, from E15.5 when they are established through $\sim 3 \mathrm{dpp}$ when they become activated to form GSCs (Aravin et al. 2008). Miwi2 is also expressed in
Sertoli cells, although this is not required for fertility (Carmell et al. 2007).

Each Piwi mutant displays unique defects in spermatogenesis. Miwi mutants are arrested at the round spermatid phase, a phenotype strongly resembling that observed in crem knockout mice (Sassone-Corsi 2000). Miwi mutants lose expression of act (activator of Crem in testis) and a range of Crem target genes, which Miwi directly binds and stabilizes. The primary defect in mili-null mice occurs within GSCs, which fail to undergo self-renewing divisions (Unhavaithaya et al. 2009). The few GSC progeny can continue to differentiation, but arrest as pachytene spermatocytes and eventually undergo apoptosis, resulting in full male sterility (Kuramochi-Miyagawa et al. 2004). Miwi2-mutant animals also display defects during meiosis, with arrest in leptotene spermatocytes and mutant spermatogonia undergoing massive apoptosis (Carmell et al. 2007). These data suggest that Miwi2 sets up an epigenetic program, which is required for GSC maintenance even after its own expression has vanished, and that lack of Miwi2 activates a DNA damage checkpoint. Consistently, mutation of Drosophila Atr and/or Chk2 is sufficient to overcome some (but not all) defects caused by mutations in the piRNA pathway components armitage or aubergine (Klattenhoff et al. 2007).

\section{The Female Germline}

Drosophila Piwi proteins are essential for oogenesis and female fertility. Piwi is required for GSC self-renewal and is expressed in both germline cells and supporting somatic tissue in the Drosophila ovary (Cox et al. 1998). Piwi mutants also display altered number of nurse cells and abnormal egg chamber polarity (Cox et al. 1998). Clonal analyses showed that somatic Piwi expression regulates GSC number and division (Cox et al. 1998, 2000; Szakmary et al. 2005), whereas germline expression of Piwi promotes GSC division in a cell-autonomous manner (Cox et al. 2000). This implies that Piwi utilizes distinct regulatory mechanisms to respond to and provide appropriate signals for GSC maintenance. Ago3 mutants display female 
sterility, with mutants laying many fewer eggs than their wild-type counterparts ( $\mathrm{Li}$ et al. 2009). In contrast to the effects of Piwi family mutations on Drosophila oogenesis, there are no known mutations of these proteins that affect fertility in female mice or humans.

Identification and Characterization of piRNAs

\section{piRNAs in Mammals}

Several groups simultaneously identified piRNAs from total testicular RNA and Piwi protein immunoprecipitates (Aravin et al. 2006; Girard et al. 2006; Grivna et al. 2006a; Lau et al. 2006; Watanabe et al. 2006). Radiolabeling of mouse testicular RNA revealed an abundant population of 28-32-nt small RNAs that were associated with MIWI and absent in miwi ${ }^{-/-}$mice. Subsequent cloning revealed 40 distinct RNAs (Grivna et al. 2006a). Five percent of this set overlapped with another set of 367 26-30-nt small RNAs isolated in an independent cloning effort (Watanabe et al. 2006). As their expression is dependent on Piwi proteins, these small RNAs were termed piwi-interacting RNAs, or piRNAs.

piRNAs are a highly complex family of small ncRNAs with more than 60,000 distinct species. Deep sequencing of RNAs immunoprecipitated with Miwi (Girard et al. 2006) and Mili (Aravin et al. 2006) revealed more than 50,000 and 15,000 additional piRNAs, respectively. Mili piRNAs are 26-28 nt, whereas Miwi piRNAs are slightly larger ( $\sim 30 \mathrm{nt})$. Both sets are biased for a $5^{\prime}$ uracil (94.2\% and 88\%). Mapping of these sequences confirmed that piRNAs are highly clustered in distinct genomic loci. Approximately 16\% of piRNA sequences mapped to repetitive elements, and none to telomeres (Girard et al. 2006). Clusters ranged in size from $\sim 1$ to $127 \mathrm{~kb}$ and displayed interesting strand characteristics. In some clusters piRNAs map exclusively to a single strand; in other clusters piRNAs may be processed from two nonoverlapping, antisense transcripts separated by a short, piRNA-depleted spacer (Aravin et al. 2006), and rat and human clusters are syntenic (Fig. 3).

piRNA expression is developmentally regulated, with different populations arising from distinct clusters in prepachytene cells, including fetal germ cells, as compared to later cell types (Aravin et al. 2007b; Kuramochi-Miyagawa et al. 2008). Accumulation of prepachytene piRNAs is Mili-dependent whereas later populations are more dependent on Miwi.

piRNAs have been identified in other mammalian species, including humans (Aravin et al. 2006; Girard et al. 2006; Lau et al. 2006), rats (Lau et al. 2006), marsupials (Devor et al. 2008), and platypus (Murchison et al. 2008). Similar to mouse piRNAs, these populations all are larger than siRNAs and miRNAs, cluster in discrete genomic loci, have a strong preference for uracil at their $5^{\prime}$ ends, and contain a phosphate group on their $5^{\prime}$ ends and a 2-Omethyl group on their $3^{\prime}$ ends.

\section{piRNAs in Insects}

The first piRNAs were identified in divergent species and characterized in Drosophila. Small RNA cloning efforts in plants (Llave et al. 2002) and trypanosomes (Djikeng et al. 2001) identified a class of 24-26-nt small RNAs, which displayed a $5^{\prime} U$ bias and evidence of RNAse IIImediated cleavage. These RNAs corresponded to highly repetitive elements and were termed repeat-associated small RNAs, or rasiRNAs. Subsequent efforts in Drosophila identified rasiRNAs that clustered in specific genomic loci and were enriched in embryos and testes (Aravin et al. 2003). The Piwi protein Aub was found to be required for expression of Suppressor of Stellate $(\mathrm{Su}(\mathrm{Ste}))$ rasiRNAs (Aravin et al. 2004), which could be coimmunoprecipitated with Piwi and Aub but not with Agol (Vagin et al. 2006). Deep sequencing of small RNAs associated with Piwi (Brennecke et al. 2007; Saito et al. 2006; Yin and Lin 2007), Aub (Brennecke et al. 2007), and Ago3 (Brennecke et al. 2007; Gunawardane et al. 2007) revealed a number of characteristics of Drosophila piRNAs.

First, distinct piRNA populations associated with each Piwi protein. Piwi-associated piRNAs were larger on average than Aub piRNAs, which were larger than Ago3 piRNAs. Second, Gunawardane et al. (2007) identified a pattern in which Piwi- and Aub-associated piRNAs 

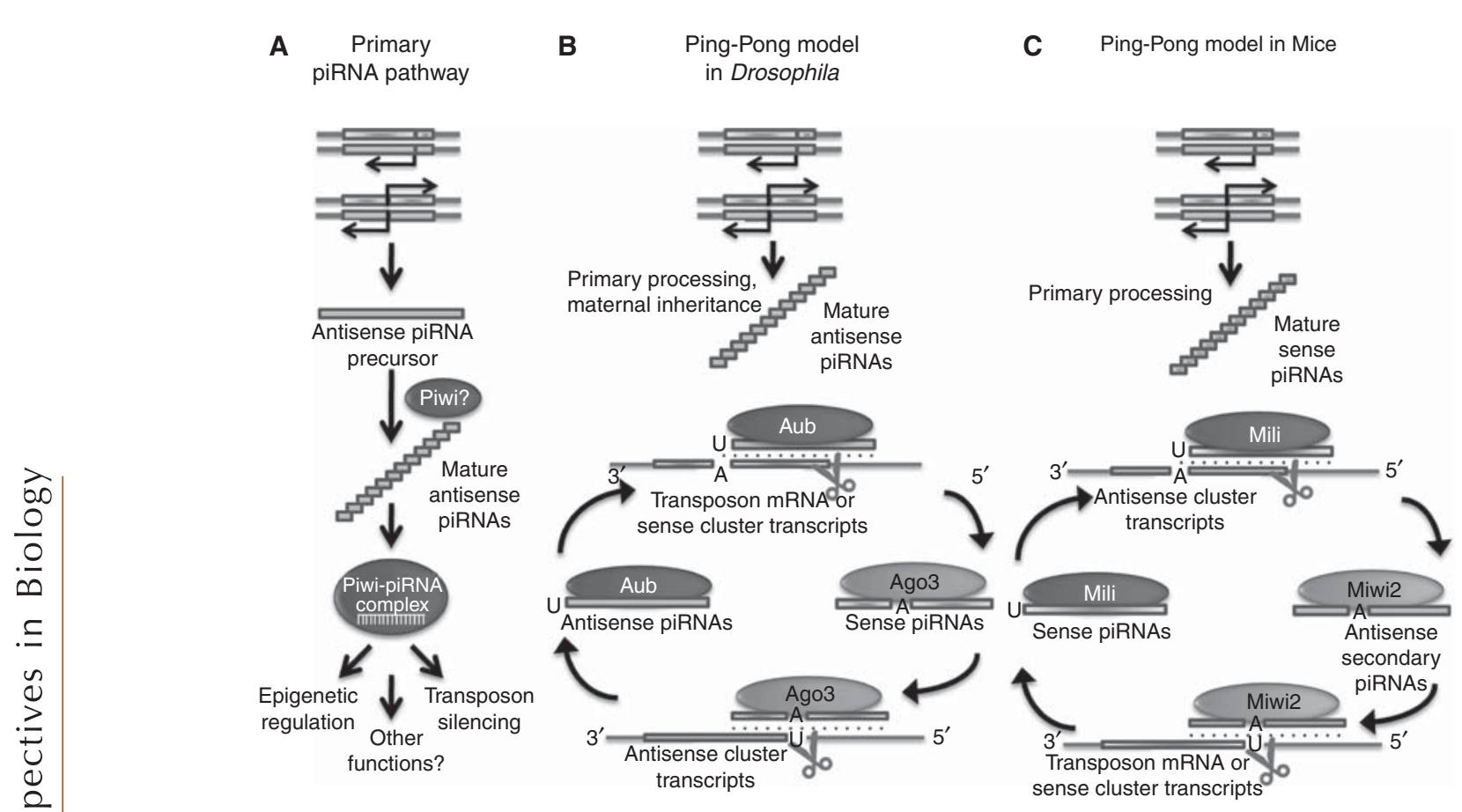

Small Noncoding RNAs in the Germline

Figure 3. Biogenesis of piRNAs. (A) In somatic cells of the Drosophila ovary, antisense piRNA precursors are produced from uni- and bidirectional piRNA clusters and processed into mature antisense piRNAs through an undefined mechanism. These piRNAs are them bound by Piwi and exert divergent effects including epigenetic regulation, transposon silencing, and others. A similar biogenesis mechanism utilizing Miwi and Mili may function in pachytene mouse testes. (B) Within the Drosophila germline, Aub and Ago3 function in a piRNA amplification loop. Antisense piRNAs are maternally inherited and/or produced from uni- and bidirectional piRNA clusters and bind to Aub. Aub-piRNA complexes catalyze degradation of transposon mRNAs and sense cluster transcripts, producing sense piRNAs that are then bound by Ago3. Ago3-piRNA complexes then produce additional antisense piRNAs through degradation of antisense cluster transcripts. $(C)$ A similar mechanism functions during generation of prepachytene mouse piRNAs. Mili binds sense piRNAs, likely produced from sense piRNA precursors. The Mili-piRNA complex mediates degradation of antisense cluster transcripts, and the resulting antisense piRNAs are bound by Miwi2. Miwi2-piRNA complexes then mediate destruction of transposon mRNAs, generating additional sense piRNAs that are incorporated into Mili-piRNA complexes.

contain a $5^{\prime} U$ at the first nucleotide position and Ago3-associated piRNAs have an adenine at their 10th nucleotide position, with a 10nucleotide complementarity between Ago3- and Aub-associated piRNAs. Furthermore, Ago3associated sequences contain a high level of transposon sense strand bias, whereas Piwiand Aub-associated piRNAs contain a high level of bias for antisense strands (Brennecke et al. 2007). These data are the "signature" of the ping-pong model of piRNA generation (see below). Third, Drosophila piRNAs map to specific genomic clusters. Most of these clusters are transposon-rich, unlike in mammals where few clusters correspond to transposonic regions. Concordantly, the proportion of piRNAs mapping to repeat-associated sequences is considerably higher in Drosophila than in mice $(\sim 50 \%$ compared to $\sim 16 \%$ ) (Aravin et al. 2006; Brennecke et al. 2007).

\section{piRNAs in Other Organisms}

piRNAs have been identified in a number of other organisms, including zebrafish, planaria, silkworm, and C. elegans. Zebrafish have two Piwi-like proteins, Ziwi and Zili, which function in germ cell maintenance and 
differentiation, meiosis, and transposon silencing. Zebrafish piRNAs are present in both male and female gametes and display the piRNA characteristics described above (Houwing et al. 2008, 2007), as do those isolated from the planaria S. mediterranea (Friedlander et al. 2009), which contains two piRNA-binding Piwi proteins (Palakodeti et al. 2008).

C. elegans possesses several diverse families of small RNAs that bind specific Piwi/Ago proteins. These include the 21U-RNAs, 22G-RNAs, 26G-RNAs, and distinct categories of primary and secondary siRNAs (Claycomb et al. 2009; Han et al. 2009; Ruby et al. 2006). 21U-RNAs are likely the piRNAs of nematodes, and were discovered through deep sequencing of RNAs with a $5^{\prime}$ monophosphate and $3^{\prime}$ hydroxyl group. 21U-RNAs invariantly contain a $5^{\prime} \mathrm{U}$ and are $21 \mathrm{bp}$ in length, are not derived from a dsRNA precursor, are largely depleted from coding sequences, and are developmentally regulated (Ruby et al. 2006). Subsequent work showed that 21U-RNAs complex with PRG-1, one of two C. elegans Piwi proteins, to regulate spermatogenesis (Batista et al. 2008; Wang and Reinke 2008).

\section{piRNA Biogenesis}

\section{The piRNA Precursor}

piRNAs are probably processed from a singlestranded RNA precursor. Individual piRNAs lay end-to-end or are slightly overlapping, suggesting that they are not nonspecific breakdown products (Aravin et al. 2006). piRNAs exhibit extreme strand bias, with little mixing of sense and antisense sequences in a particular cluster. This in turn implies that piRNAs in a specific cluster are derived from a single transcript. Consistently, long RNA transcripts corresponding to piRNA clusters have been identified (Lau et al. 2006). Interestingly, these precursors are probably not polyadenylated (Ro et al. 2007).

Recent findings have suggested possible mechanisms that may regulate the transcription of specific precursors. In Drosophila, a member of the Heterochromatin Protein 1 (HP1) subfamily of chromo box proteins, Rhino, physically associates with DNA at the $1 / 42 \mathrm{AB}$
piRNA cluster and is required for transcription of precursors from this region. Rhino mutations result in transposon activation and female sterility (Volpe et al. 2001; Klattenhoff et al. 2009). Its presence may displace other HP proteins, preventing them from repressing expression at these loci (Klattenhoff et al. 2009).

\section{Processing of the Precursor}

There is evidence indicating that piRNAs are produced from their precursors by the cleavage activity of Piwi proteins rather than Dicer. Mutation of miwi and mili severely reduces levels of mature piRNAs but not miRNAs or Dicer (Grivna et al. 2006a, 2006b; Aravin et al. 2007b), although it is not known if precursors are properly transcribed. In Drosophila, piRNAs are expressed normally in Dicer 1 and Dicer $2 \mathrm{mu}-$ tants (Vagin et al. 2006). Piwi, Ago3, and Aub all contain slicer activity in vitro, arguing that they are capable of generating mature piRNAs from potential precursors (Gunawardane et al. 2007; Saito et al. 2006). The Drosophila nucleases squash and zucchini play roles in pingpong dependent and independent processing of piRNAs, respectively (Pane et al. 2007; Malone et al. 2009; Saito et al. 2009), although how they fit into these pathways is unknown.

\section{The Ping-Pong Model: Posttranscriptional Amplification}

The ping-pong "signature" is particularly prevalent among Aub- and Ago3-piRNAs. Piwiassociated piRNAs, although maintaining an antisense bias, do not display evidence of pingpong-based biogenesis (Malone et al. 2009). Many piRNA clusters correspond to various transposonic "graveyards," which are transcribed as a precursor in an antisense orientation. This precursor is then processed into mature piRNAs by Aub (and possibly Piwi), either directly or in a processing complex of unknown composition. These mature piRNAs contain complementarity to active transposons, leading to their targeting and cleavage that produces sense piRNAs. These sense piRNAs are complementary to the antisense precursors, leading to their cleavage and feedforward 
production of more antisense piRNAs. Initial antisense piRNAs may be maternally contributed (Lin 2007; Brennecke et al. 2008), although the chicken-and-egg problem of how the first piRNAs are derived has yet to be fully resolved.

There is considerable genetic evidence in favor of ping-pong-based amplification for a subset of piRNAs. First, aubergine mutants display a shift in the overall size of the piRNA population to that of Piwi piRNAs and no longer have a ping-pong signature in their germline piRNAs (Malone et al. 2009). Second, ago3 heterozygotes contained only $\sim 40 \%$ of the sense piRNAs as compared to wild-type controls, whereas antisense piRNAs were not affected to the same degree. This suggests that Ago3 is limiting, and likely required, for the production of sense piRNAs. Third, antisense piRNAs were severely depleted in mutants containing no viable ago3, implying that Ago3 acts to stabilize and/or amplify this population ( $\mathrm{Li}$ et al. 2009). Interestingly, antisense Piwi-bound piRNAs were only slightly affected in ago3 heterozygotes versus mutants, suggesting that Piwi-piRNAs are mostly generated by a nonping-pong mechanism.

Prepachytene piRNAs in mice also display a ping-pong signature. In Mili and Miwi2 immunoprecipitates from male 16.5 -dpc gonads, $46 \%$ and $76 \%$ of piRNAs corresponded to transposon sequences, contained a 10 bp-overlap in their $5^{\prime}$ ends and an adenine at their 10th position (Aravin et al. 2007b). Mili preferentially interacts with sense sequences whereas Miwi2associated piRNAs tend to have an antisense bias. piRNA precursors may be processed by Mili, generating primary piRNAs, which then direct cleavage of antisense transcripts in Miwi2 complexes to generate secondary piRNAs. Note that this is the opposite of what is proposed in Drosophila. Consistently, mili mutants have no Miwi2-associated piRNAs (Aravin et al. 2008).

\section{Ping-Pong-Independent piRNA Generation}

The ping-pong mechanism is highly conserved evolutionarily, functioning in organisms as diverse as Nematostella (sea anenome) and
Amphimedon (sponge) (Grimson et al. 2008). However, the ping-pong mechanism is not the lone, or possibly even primary, mechanism of piRNA biogenesis. The profiling of piRNAs in Drosophila revealed that some piRNAs are mapped to 26 specific transposons and are predominantly antisense, even in the absence of ago3. They mainly bound Piwi rather than Aub or Ago3, and mapped predominantly to one particular locus termed flamenco in which transposons are arranged in an antisense manner. Piwi is required for silencing transposons within the flamenco locus (Sarot et al. 2004), including gypsy which is active within somatic cells of the ovary. Thus a distinct, Piwi-dependent piRNA generation pathway operates within somatic cells (and, to a lesser extent, within germ cells as well) (Li et al. 2009; Malone et al. 2009).

Ping-pong-independent processing of the flamenco locus is reminiscent of mouse pachytene piRNA clusters. Only $\sim 17 \%$ of piRNAs from these clusters correspond to transposons, whereas repetitive sequences comprise $\sim 50 \%$ of the cloned prepachytene piRNAs. Even in Drosophila, only $\sim 50 \%$ of total piRNAs potentially target transposons. In sum, these data show that the piRNA pathway utilizes multiple biogenic mechanisms.

\section{Regulatory Functions of Piwi Proteins and piRNAs}

\section{Piwis and piRNAs as Epigenetic Regulators}

Piwi proteins function in epigenetic regulation. In Drosophila, Piwi and Aub regulate positioneffect variegation (PEV) (Pal-Bhadra et al. 2004), in which a euchromatic gene is silenced when localized in the vicinity of a heterochromatic region (Dorer and Henikoff 1994; Martin-Morris et al. 1997). An artificial example of PEV is observed by tandem insertion of the white gene, leading to transcriptional silencing of the transgene and red eye color. Piwi and Aub are required for heterochromatin organization (Pal-Bhadra et al. 2004). Furthermore, HPla and Piwi physically interact in vitro and in vivo. Piwi directly interacts with 
chromosomes and is localized to several heterochromatic regions. As PEV is lost when Piwi and HPla cannot physically interact (BrowerToland et al. 2007), it is evident that Piwi and Hpla interact to achieve epigenetic regulation. In this pathway, it is possible that the PiwipiRNA complex guides HP1a and other epigenetic factors to their target sequences in the genome (Lin and Yin 2008).

Support for this hypothesis comes from a recent study in which Piwi and a specific piRNA were found to play an epigenetic activation role specifically at the piRNA target site (Yin and Lin 2007). This study focused on a genomic sequence in the subtelomeric region of the right arm of the third chromosome (3R-TAS) that corresponds uniquely to a piRNA called the 3R-TAS1 piRNA. 3R-TAS1 chromatin is bound by Piwi and is partially euchromatic. However, in piwi mutants it became heterochromatic, indicating the role of Piwi in promoting the euchromatic state of 3R-TAS1. In support of this, the expression of the 3R-TAS1 piRNA is lost in piwi mutant flies. In addition, the expression of a protein reporter gene inserted immediately downstream from the 3R-TAS1corresponding site is also silenced. Furthermore, this epigenetic change is sharply confined within the vicinity of the 3R-TAS1 DNA sequence, suggesting that the piRNA renders Piwi-specific binding to its complementary 3R-TAS sequence. Interestingly, insertion of a Pelement 128 bp downstream from the 3R-TAS1 sequence rescued the 3R-TAS1 piRNA expression in the mutant background, restored the euchromatic character of 3R-TAS1 DNA, and partially rescued effects of piwi mutation of germline stem cell maintenance (Yin and Lin 2007). These results correlate the expression of 3R-TAS1 piRNA to the epigenetic state of its target genomic sequence.

The recruitment of HP1a by Piwi-piRNA complexes, however, cannot easily explain the opposite effect of Piwi at different sites of the genome because HP1a is mainly known to promote heterochromatin formation. Other proteins might be recruited by Piwi-piRNA complexes to different sites. For example, the HP-like protein Rhino is specifically expressed in the female germline (Volpe et al. 2001; Vermaak et al. 2005). Rhino mutants specifically overexpress RNAs of transposons present in double-stranded piRNA clusters, where Rhino is physically present in a wild-type background (Klattenhoff et al. 2009). These results suggest different HP proteins may dictate a permissive vs. nonpermissive chromatin environment and could explain how Piwi could be important for both heterochromatin formation and epigenetic activation (Yin and Lin 2007).

Epigenetic functions of Piwi proteins are conserved in mouse testes, where they are required for establishment of DNA methylation patterns. Mice mutant for dnmt3l (DNA methyltransferase $3 \mathrm{~L}$, which is required for de novo DNA methylation) display a phenotype similar to mili mutants, including loss of transposon suppression and an increase in transposonderived piRNAs (Bourc'his and Bestor 2004; Aravin et al. 2008). Mili and miwiz mutant animals show greatly reduced levels of CpG methylation in PGCs, with concordant increases in transposon expression (Kuramochi-Miyagawa et al. 2008). These studies also suggest that specific epigenetic mechanisms mediated by Piwi proteins in mammalian systems are at least partially different from that in Drosophila.

\section{Regulation of Transposon Activity Depends on Piwi Protein Localization}

Piwi proteins are well characterized for their function in silencing transposition, which has been extensively reviewed (Aravin et al. 2007a; Thomson and Lin 2009). Here, we cover the latest developments in Piwi/piRNA-mediated transposon silencing, and focus on how a piRNA-mediated scanning and silencing mechanism might operate. Clues to this question arise from work utilizing rhino mutants. In these flies, Piwi mostly retains nuclear expression whereas Ago3 and Aub are mislocalized (Klattenhoff et al. 2009). In a wild-type background, these two proteins are localized to a perinuclear structure called the nuage. The function of the nuage has not conclusively been shown, but proper nuage formation is apparently critical for transposon silencing. 
Mutations in genes that disrupt nuage formation, such as rhino, maelstrom, and krimper, invariably result in elevated levels of transposon transcripts and defects in piRNA production (Findley et al. 2003; Lim and Kai 2007; Klattenhoff et al. 2009). Additionally, localization of Aub and Ago3 to nuage is interdependent (Li et al. 2009), and mutation of either gene also leads to defects in nuage formation and piRNA biogenesis. Thus, nuage assembly and piRNA-mediated silencing appear to be coregulated.

These observations, coupled with the fact that expression of protein-coding transcripts containing transposons in their introns does not seem to be affected by piRNA pathway mutations, led (Klattenhoff et al. 2009) to propose that mature RNA transcripts are exported from the nucleus and are scanned for homology to transposons in the nuage. Protein-coding transcripts pass through, as any transposons containing intronic sequences have been removed by splicing. Transposon transcripts and piRNA precursors, however, are recognized and destroyed by piRNAs in an Ago3/Aubmediated ping-pong cycle. An alternative explanation may lie in the nature of the primary transcript itself; mRNAs contain polyadenylated $3^{\prime}$ ends, whereas primary piRNA precursors apparently lack this modification (Ro et al. 2007). This may form the basis for recognition of these sequences to recruit the appropriate scanning apparatus. This general model of nuage-based scanning could potentially function in mammalian testes as well.

Proper localization of piRNA pathway components is critical for piRNA-mediated transposon silencing in mouse testis. In adult testes, Miwi and Mili are both localized to the chromatoid body, a mammalian version of the nuage (Kotaja and Sassone-Corsi 2007; see also Voronina et al. 2011). In gonocytes, Mili is located to a specialized form of nuage called the intermitochondrial cement, where it forms granules termed "pi-bodies" (Aravin et al. 2009). Within pi-bodies, Mili interacts with the Tudor domain-containing protein Tdrd1, whose localization and expression depends on Mili (Wang et al. 2009). Deletion of Tdrd1 results in male sterility (Chuma et al. 2006) with severe disruption of the ping-pong cycle. In addition, Miwi2-associated antisense piRNAs corresponding to transposonic sequences are lost, and cellular transcripts instead comprise the vast majority of cloned piRNAs (although overall piRNA biogenesis is intact (Reuter et al. 2009; Vagin et al. 2009; Wang et al. 2009). Several other Tudor domain-containing proteins also interact with Mili, Miwi, and Miwi2, including Tdrd2, Tdrd6, Tdrd7, and Tdrd9 (Hosokawa et al. 2007; Chen et al. 2009; Vagin et al. 2009). Deletion of Tdrd6 and Tdrd9 also result in male sterility (Shoji et al. 2009; Vasileva et al. 2009). Tdrd9 specifically interacts with Miwi2 in gonocyte-specific structures termed "piP-bodies" (Aravin et al. 2009; Shoji et al. 2009). Mael is another component of piP-bodies and is required for Miwi2 and Tdrd 9 localization. Interestingly, pi-body components Mili and Tdrd1 are required for proper localization of the piP-body components Miwi2, Tdrd9, and Mael, although the converse is not true (Aravin et al. 2008, 2009). Deletion of Mael and Tdrd 9 also lead to male sterility and transposon derepression (Soper et al. 2008; Shoji et al. 2009), and piRNAs from Tdrd9 mutants are highly enriched for sense-strand LINEelement sequences (Shoji et al. 2009). Thus, piand piP-bodies may act as a sort of "base station" in which the core piRNA machinery interacts with nuage components such as Tdrd proteins and $\mathrm{MVH}$. These proteins may recruit specific transcripts and/or RNA populations to play roles in piRNA-mediated processes and to ensure correct targeting of transposons for degradation. Despite this, it remains unknown how these distinct granules coordinate their activities to accomplish their functions.

piP bodies may function to coordinate piRNA biogenesis and translational repression. piP bodies are a variant of P-bodies, which act in mRNA storage, decay, and translational regulation (Eulalio et al. 2007), and contain several P-body components such as GW182, DDX6, and XRN1 (Aravin et al. 2009; Shoji et al. 2009). Thus, piP bodies lie at the intersection of the piRNA pathway and mRNA processing, and may act in translational regulation. 


\section{The Role of Piwi Proteins and piRNAs in Translation and mRNA Turnover}

Mammalian Piwi proteins are predominantly cytoplasmic and cofractionate with polysomes, suggesting a potential role in translational regulation (Grivna et al. 2006a,b; Wang et al. 2009). Miwi associates with mRNAs and piRNAs in polysomes, suggesting that Miwi-bound piRNAs may regulate translation or stability of specific transcripts (Grivna et al. 2006b). The control of Piwi proteins toward the mRNA stability is evident by the fact that Miwi-bound mRNAs are abrogated in miwi-null animals (Deng and Lin 2002). Furthermore, the following observations indicate that Piwi proteins may be involved in translational regulation. First, Miwi associates with the cap-binding complex involved in translational initiation, and also with Dicer (Grivna et al. 2006b). Miwi mutant animals display abnormal biogenesis of a subset of miRNAs, suggesting that Miwi may regulate translation through miRNA-mediated mechanisms as well as directly through its interactions with mRNA cap-binding proteins. Second, mili mutants display defects in global protein translation. Isolated $7 \mathrm{dpp}$ seminiferous tubules, which contain only GSCs, display greatly reduced protein synthesis in mili mutants despite containing normal mRNA levels (Unhavaithaya et al. 2009). At the molecular level, Mili interacts with the translation initiation factor eIF3a and with the eIF4E- and eIF4G-containing m7G cap-binding complex. Thus, Mili may be required for various aspects of translation, and defects in these aspects may lead to the defects in GSC self-renewal observed in mili-null animals (Unhavaithaya et al. 2009).

Some piRNAs derived from mRNAs may function in translational repression. Recent studies have shown that these piRNAs are disproportionately derived from the $3^{\prime}$ UTRs of specific classes of genes (Robine et al. 2009; Saito et al. 2009). These piRNAs are senseoriented, are not generated through a pingpong mechanism, and are present in Drosophila, Xenopus, and mouse (Robine et al. 2009), even though how transcripts are selected for processing is unclear. The $3^{\prime}$ UTR of traffic jam ( $\left.t j\right)$ generates a large amount of piRNAs (compared to other $3^{\prime}$ UTRs). Clonal analysis in ovary follicles showed that piwi mutant follicles have elevated levels of TJ (Robine et al. 2009). Interestingly, tj positively regulates Piwi expression in somatic gonadal tissue, and may negatively regulate Piwi within the germline itself (Saito et al. 2009). As 35\% of small RNAs from 10 dpp testes correspond to $3^{\prime}$ UTRs (Robine et al. 2009), it is tempting to speculate that this is a general mechanism for translational repression; however, this remains speculation, and this mechanism may be specific to the $t j$ mRNA.

\section{CONCLUDING REMARKS}

As reviewed above, three families of small noncoding RNAs have emerged as key regulators of cellular and developmental processes, with their function highlighted in the germline. Among them, miRNAs control various aspects of germline development, from germline specification to GSC self-renewal and gametogenesis. EndosiRNAs represent a novel, exciting class of small RNAs also with critical roles within the germline. They are known to protect and maintain genomic integrity from the assault of mobile genetic elements such as transposons, a role they share with the germline-specific piRNAs. However, their role in regulating gene expression awaits further exploration. By comparison, the understanding of the piRNA pathway is still at the beginning stage, with fundamental biological questions remaining unanswered. For example, how are piRNAs generated? What exact roles do these molecules play in epigenetic and translational regulation? How do these mechanisms contribute to biological functions such as GSC maintenance, transposon silencing, and meiosis? The coming years will doubtlessly provide exciting answers to these questions and many more.

\section{REFERENCES}

\footnotetext{
Aravin AA, Lagos-Quintana M, Yalcin A, Zavolan M, Marks D, Snyder B, Gaasterland T, Meyer J, Tuschl T. 2003. The small RNA profile during Drosophila melanogaster development. Dev Cell 5: 337-350.
} 
Aravin AA, Klenov MS, Vagin VV, Bantignies F, Cavalli G, Gvozdev VA. 2004. Dissection of a natural RNA silencing process in the Drosophila melanogaster germ line. Mol Cell Biol 24: 6742-6750.

Aravin A, Gaidatzis D, Pfeffer S, Lagos-Quintana M, Landgraf P, Iovino N, Morris P, Brownstein MJ, Kuramochi-Miyagawa S, Nakano T, et al. 2006. A novel class of small RNAs bind to MILI protein in mouse testes. Nature 442: 203-207.

Aravin AA, Hannon GJ, Brennecke J. 2007a. The PiwipiRNA pathway provides an adaptive defense in the transposon arms race. Science 318: 761-764.

Aravin AA, Sachidanandam R, Girard A, Fejes-Toth K, Hannon GJ. 2007b. Developmentally regulated piRNA clusters implicate MILI in transposon control. Science 316: 744-747.

Aravin AA, Sachidanandam R, Bourc'his D, Schaefer C Pezic D, Toth KF, Bestor T, Hannon GJ. 2008. A piRNA pathway primed by individual transposons is linked to de novo DNA methylation in mice. Mol Cell 31: 785-799.

Aravin AA, van der Heijden GW, Castaneda J, Vagin VV, Hannon GJ, Bortvin A. 2009. Cytoplasmic compartmentalization of the fetal piRNA pathway in mice. PLoS Genet 5: e1000764.

Batista PJ, Ruby JG, Claycomb JM, Chiang R, Fahlgren N, Kasschau KD, Chaves DA, Gu W, Vasale JJ, Duan S, et al. 2008. PRG-1 and 21U-RNAs interact to form the piRNA complex required for fertility in C. elegans. Mol Cell 31: 67-78.

Bernstein E, Caudy AA, Hammond SM, Hannon GJ. 2001. Role for a bidentate ribonuclease in the initiation step of RNA interference. Nature 409: 363-366.

Beyret E, Lin H. 2008. Piwi-interacting RNAs (piRNAs). In MicroRNAs from basic science to disease biology (ed. Appasani K), pp. 489-496. Cambridge University Press, Cambridge.

Billy E, Brondani V, Zhang H, Muller U, Filipowicz W. 2001. Specific interference with gene expression induced by long, double-stranded RNA in mouse embryonal teratocarcinoma cell lines. Proc Natl Acad Sci 98: 14428-14433.

Bourc'his D, Bestor TH. 2004. Meiotic catastrophe and retrotransposon reactivation in male germ cells lacking Dnmt3L. Nature 431: 96-99.

Brennecke J, Aravin AA, Stark A, Dus M, Kellis M, Sachidanandam R, Hannon GJ. 2007. Discrete small RNAgenerating loci as master regulators of transposon activity in Drosophila. Cell 128: 1089-1103.

Brennecke J, Malone CD, Aravin AA, Sachidanandam R, Stark A, Hannon GJ. 2008. An epigenetic role for maternally inherited piRNAs in transposon silencing. Science 322: $1387-1392$.

Brower-Toland B, Findley SD, Jiang L, Liu L, Yin H, Dus M, Zhou P, Elgin SC, Lin H. 2007. Drosophila PIWI associates with chromatin and interacts directly with HP1a. Genes Dev 21: 2300-2311.

Carmell MA, Girard A, van de Kant HJ, Bourc'his D, Bestor TH, de Rooij DG, Hannon GJ. 2007. MIWI2 is essential for spermatogenesis and repression of transposons in the mouse male germline. Dev Cell 12: 503-514.
Chen CZ, Li L, Lodish HF, Bartel DP. 2004. MicroRNAs modulate hematopoietic lineage differentiation. Science 303: $83-86$.

Chen C, Jin J, James DA, Adams-Cioaba MA, Park JG, Guo Y, Tenaglia E, Xu C, Gish G, Min J, et al. 2009. Mouse Piwi interactome identifies binding mechanism of Tdrkh Tudor domain to arginine methylated Miwi. Proc Natl Acad Sci 106: 20336-20341.

Cheng LC, Pastrana E, Tavazoie M, Doetsch F. 2009. miR-124 regulates adult neurogenesis in the subventricular zone stem cell niche. Nat Neurosci 12: 399-408.

Chuma S, Hosokawa M, Kitamura K, Kasai S, Fujioka M, Hiyoshi M, Takamune K, Noce T, Nakatsuji N. 2006. Tdrd1/Mtr-1, a tudor-related gene, is essential for male germ-cell differentiation and nuage/germinal granule formation in mice. Proc Natl Acad Sci 103: 15894-15899.

Chung WJ, Okamura K, Martin R, Lai EC. 2008. Endogenous RNA interference provides a somatic defense against Drosophila transposons. Curr Biol 18: 795-802.

Claycomb JM, Batista PJ, Pang KM, Gu W, Vasale JJ, van Wolfswinkel JC, Chaves DA, Shirayama M, Mitani S, Ketting RF, et al. 2009. The Argonaute CSR-1 and its 22G-RNA cofactors are required for holocentric chromosome segregation. Cell 139: 123-134.

Cox DN, Chao A, Baker J, Chang L, Qiao D, Lin H. 1998. A novel class of evolutionarily conserved genes defined by piwi are essential for stem cell self-renewal. Genes Dev 12: $3715-3727$.

Cox DN, Chao A, Lin H. 2000. piwi encodes a nucleoplasmic factor whose activity modulates the number and division rate of germline stem cells. Development 127: 503-514.

Czech B, Malone CD, Zhou R, Stark A, Schlingeheyde C, Dus M, Perrimon N, Kellis M, Wohlschlegel JA, Sachidanandam R, et al. 2008. An endogenous small interfering RNA pathway in Drosophila. Nature 453: 798-802.

Deng W, Lin H. 2002. miwi, a murine homolog of piwi, encodes a cytoplasmic protein essential for spermatogenesis. Dev Cell 2: 819-830.

Devor EJ, Huang L, Samollow PB. 2008. PiRNA-like RNAs in the marsupial Monodelphis domestica identify transcription clusters and likely marsupial transposon targets. Mamm Genome 19: 581-586.

Djikeng A, Shi H, Tschudi C, Ullu E. 2001. RNA interference in Trypanosoma brucei: Cloning of small interfering RNAs provides evidence for retroposon-derived 24-26nucleotide RNAs. RNA 7: 1522-1530.

Dorer DR, Henikoff S. 1994. Expansions of transgene repeats cause heterochromatin formation and gene silencing in Drosophila. Cell 77: 993-1002.

Elbashir SM, Harborth J, Lendeckel W, Yalcin A, Weber K, Tuschl T. 2001a. Duplexes of 21-nucleotide RNAs mediate RNA interference in cultured mammalian cells. Nature 411: 494-498.

Elbashir SM, Lendeckel W, Tuschl T. 2001b. RNA interference is mediated by 21- and 22-nucleotide RNAs. Genes Dev 15: 188-200.

Elbashir SM, Martinez J, Patkaniowska A, Lendeckel W, Tuschl T. 2001c. Functional anatomy of siRNAs for mediating efficient RNAi in Drosophila melanogaster embryo lysate. $E M B O J$ 20: 6877-6888. 
Eulalio A, Behm-Ansmant I, Izaurralde E. 2007. P bodies: At the crossroads of post-transcriptional pathways. Nat Rev Mol Cell Biol 8: 9-22.

Findley SD, Tamanaha M, Clegg NJ, Ruohola-Baker H. 2003. Maelstrom, a Drosophila spindle-class gene, encodes a protein that colocalizes with Vasa and RDE1/ AGO1 homolog, Aubergine, in nuage. Development 130: 859-871.

Fire A, Xu S, Montgomery MK, Kostas SA, Driver SE, Mello CC. 1998. Potent and specific genetic interference by double-stranded RNA in Caenorhabditis elegans. Nature 391: 806-811.

Forstemann K, Tomari Y, Du T, Vagin VV, Denli AM, Bratu DP, Klattenhoff C, Theurkauf WE, Zamore PD. 2005. Normal microRNA maturation and germ-line stem cell maintenance requires Loquacious, a double-stranded RNA-binding domain protein. PLoS Biol 3: e236.

Friedlander MR, Adamidi C, Han T, Lebedeva S, Isenbarger TA, Hirst M, Marra M, Nusbaum C, Lee WL, Jenkin JC, et al. 2009. High-resolution profiling and discovery of planarian small RNAs. Proc Natl Acad Sci 106: 11546-11551.

Gangaraju VK, Lin H. 2009. MicroRNAs: Key regulators of stem cells. Nat Rev Mol Cell Biol 10: 116-125.

Ghildiyal M, Seitz H, Horwich MD, Li C, Du T, Lee S, Xu J, Kittler EL, Zapp ML, Weng Z, et al. 2008. Endogenous siRNAs derived from transposons and mRNAs in Drosophila somatic cells. Science 320: 1077-1081.

Girard A, Sachidanandam R, Hannon GJ, Carmell MA. 2006. A germline-specific class of small RNAs binds mammalian Piwi proteins. Nature 442: 199-202.

Golden DE, Gerbasi VR, Sontheimer EJ. 2008. An inside job for siRNAs. Mol Cell 31: 309-312.

Grimson A, Srivastava M, Fahey B, Woodcroft BJ, Chiang HR, King N, Degnan BM, Rokhsar DS, Bartel DP. 2008. Early origins and evolution of microRNAs and Piwiinteracting RNAs in animals. Nature 455: 1193-1197.

Grishok A, Pasquinelli AE, Conte D, Li N, Parrish S, Ha I, Baillie DL, Fire A, Ruvkun G, Mello CC. 2001. Genes and mechanisms related to RNA interference regulate expression of the small temporal RNAs that control C. elegans developmental timing. Cell 106: 23-34.

Grivna ST, Beyret E, Wang Z, Lin H. 2006a. A novel class of small RNAs in mouse spermatogenic cells. Genes Dev 20: 1709-1714.

Grivna ST, Pyhtila B, Lin H. 2006b. MIWI associates with translational machinery and PIWI-interacting RNAs (piRNAs) in regulating spermatogenesis. Proc Natl Acad Sci 103: 13415-13420.

Gunawardane LS, Saito K, Nishida KM, Miyoshi K, Kawamura Y, Nagami T, Siomi H, Siomi MC. 2007. A slicermediated mechanism for repeat-associated siRNA $5^{\prime}$ end formation in Drosophila. Science 315: 1587-1590.

Han T, Manoharan AP, Harkins TT, Bouffard P, Fitzpatrick C, Chu DS, Thierry-Mieg D, Thierry-Mieg J, Kim JK. 2009. 26G endo-siRNAs regulate spermatogenic and zygotic gene expression in Caenorhabditis elegans. Proc Natl Acad Sci 106: 18674-18679.

Hatfield SD, Shcherbata HR, Fischer KA, Nakahara K, Carthew RW, Ruohola-Baker H. 2005. Stem cell division is regulated by the microRNA pathway. Nature 435: 974-978.

Hosokawa M, Shoji M, Kitamura K, Tanaka T, Noce T, Chuma S, Nakatsuji N. 2007. Tudor-related proteins TDRD1/MTR-1, TDRD6 and TDRD7/TRAP: Domain composition, intracellular localization, and function in male germ cells in mice. Dev Biol 301: 38-52.

Houwing S, Kamminga LM, Berezikov E, Cronembold D, Girard A, van den Elst H, Filippov DV, Blaser H, Raz E, Moens CB, et al. 2007. A role for Piwi and piRNAs in germ cell maintenance and transposon silencing in zebrafish. Cell 129: 69-82.

Houwing S, Berezikov E, Ketting RF. 2008. Zili is required for germ cell differentiation and meiosis in zebrafish. EMBO J 27: 2702-2711.

Hutvagner G, McLachlan J, Pasquinelli AE, Balint E, Tuschl T, Zamore PD. 2001. A cellular function for the RNAinterference enzyme Dicer in the maturation of the let-7 small temporal RNA. Science 293: 834-838.

Iovino N, Pane A, Gaul U. 2009. miR-184 has multiple roles in Drosophila female germline development. Dev Cell 17: $123-133$.

Kawamura Y, Saito K, Kin T, Ono Y, Asai K, Sunohara T, Okada TN, Siomi MC, Siomi H. 2008. Drosophila endogenous small RNAs bind to Argonaute 2 in somatic cells. Nature 453: 793-797.

Kim VN, Han J, Siomi MC. 2009. Biogenesis of small RNAs in animals. Nat Rev Mol Cell Biol 10: 126-139.

Klattenhoff C, Bratu DP, McGinnis-Schultz N, Koppetsch BS, Cook HA, Theurkauf WE. 2007. Drosophila rasiRNA pathway mutations disrupt embryonic axis specification through activation of an ATR/Chk2 DNA damage response. Dev Cell 12: 45-55.

Klattenhoff C, Xi H, Li C, Lee S, Xu J, Khurana JS, Zhang F, Schultz N, Koppetsch BS, Nowosielska A, et al. 2009. The Drosophila HP1 homolog Rhino is required for transposon silencing and piRNA production by dual-strand clusters. Cell 138: 1137-1149.

Knight SW, Bass BL. 2001. A role for the RNase III enzyme DCR-1 in RNA interference and germ line development in Caenorhabditis elegans. Science 293: 2269-2271.

Kotaja N, Sassone-Corsi P. 2007. The chromatoid body: A germ-cell-specific RNA-processing centre. Nature Reviews Mol Cell Biol 8: 85-90.

Kuramochi-Miyagawa S, Kimura T, Ijiri TW, Isobe T, Asada N, Fujita Y, Ikawa M, Iwai N, Okabe M, Deng W, et al. 2004. Mili, a mammalian member of piwi family gene, is essential for spermatogenesis. Development 131: 839-849.

Kuramochi-Miyagawa S, Watanabe T, Gotoh K, Totoki Y, Toyoda A, Ikawa M, Asada N, Kojima K, Yamaguchi Y, Ijiri TW, et al. 2008. DNA methylation of retrotransposon genes is regulated by Piwi family members MILI and MIWI2 in murine fetal testes. Genes Dev 22: 908-917.

Lagos-Quintana M, Rauhut R, Lendeckel W, Tuschl T. 2001. Identification of novel genes coding for small expressed RNAs. Science 294: 853-858.

Lau NC, Lim LP, Weinstein EG, Bartel DP. 2001. An abundant class of tiny RNAs with probable regulatory roles in Caenorhabditis elegans. Science 294: 858-862. 
Lau NC, Seto AG, Kim J, Kuramochi-Miyagawa S, Nakano T, Bartel DP, Kingston RE. 2006. Characterization of the piRNA complex from rat testes. Science 313: 363-367.

Lee RC, Ambros V. 2001. An extensive class of small RNAs in Caenorhabditis elegans. Science 294: 862-864.

Li C, Vagin VV, Lee S, Xu J, Ma S, Xi H, Seitz H, Horwich MD, Syrzycka M, Honda BM, et al. 2009. Collapse of germline piRNAs in the absence of Argonaute 3 reveals somatic piRNAs in flies. Cell 137: 509-521.

Lim AK, Kai T. 2007. Unique germ-line organelle, nuage, functions to repress selfish genetic elements in Drosophila melanogaster. Proc Natl Acad Sci104: 6714-6719.

Lin H. 2007. piRNAs in the germ line. Science 316: 397.

Lin H, Spradling AC. 1997. A novel group of pumilio mutations affects the asymmetric division of germline stem cells in the Drosophila ovary. Development 124: 2463 2476.

Lin H, Yin H. 2008. A novel epigenetic mechanism in Drosophila somatic cells mediated by Piwi and piRNAs. Cold Spring Harb Symp Quant Biol 73: 273-281.

Llave C, Kasschau KD, Rector MA, Carrington JC. 2002. Endogenous and silencing-associated small RNAs in plants. Plant Cell 14: 1605-1619.

Lu J, Getz G, Miska EA, Alvarez-Saavedra E, Lamb J, Peck D, Sweet-Cordero A, Ebert BL, Mak RH, Ferrando AA, et al. 2005. MicroRNA expression profiles classify human cancers. Nature 435: 834-838.

Malone CD, Brennecke J, Dus M, Stark A, McCombie WR, Sachidanandam R, Hannon GJ. 2009. Specialized piRNA pathways act in germline and somatic tissues of the Drosophila ovary. Cell 137: 522-535.

Martin-Morris LE, Csink AK, Dorer DR, Talbert PB, Henikoff S. 1997. Heterochromatic trans-inactivation of Drosophila white transgenes. Genetics 147: 671-677.

Martinez J, Patkaniowska A, Urlaub H, Luhrmann R, Tuschl T. 2002. Single-stranded antisense siRNAs guide target RNA cleavage in RNAi. Cell 110: 563-574.

Megosh HB, Cox DN, Campbell C, Lin H. 2006. The role of PIWI and the miRNA machinery in Drosophila germline determination. Curr Biol 16: 1884-1894.

miRBase http://microrna.sanger.ac.uk/cgi-bin/sequences/ browse.pl. Manchester (UK): Sanger Institute Wellcome Trust, -.c.J., 2009. Available from: http://microrna. sanger.ac.uk.

Murchison EP, Kheradpour P, Sachidanandam R, Smith C, Hodges E, Xuan Z, Kellis M, Grutzner F, Stark A, Hannon GJ. 2008. Conservation of small RNA pathways in platypus. Genome Res 18: 995-1004.

Okamura K, Hagen JW, Duan H, Tyler DM, Lai EC. 2007. The mirtron pathway generates microRNA-class regulatory RNAs in Drosophila. Cell 130: 89-100.

Okamura K, Balla S, Martin R, Liu N, Lai EC. 2008a. Two distinct mechanisms generate endogenous siRNAs from bidirectional transcription in Drosophila melanogaster. Nat Struct Mol Biol 15: 998.

Okamura K, Chung WJ, Ruby JG, Guo H, Bartel DP, Lai EC. 2008b. The Drosophila hairpin RNA pathway generates endogenous short interfering RNAs. Nature 453: 803-806.

Palakodeti D, Smielewska M, Lu YC, Yeo GW, Graveley BR. 2008. The PIWI proteins SMEDWI-2 and SMEDWI-3 are required for stem cell function and piRNA expression in planarians. RNA 14: 1174-1186.

Pal-Bhadra M, Leibovitch BA, Gandhi SG, Rao M, Bhadra U, Birchler JA, Elgin SC. 2004. Heterochromatic silencing and HP1 localization in Drosophila are dependent on the RNAi machinery. Science 303: 669-672.

Pane A, Wehr K, Schupbach T. 2007. zucchini and squash encode two putative nucleases required for rasiRNA production in the Drosophila germline. Dev Cell 12: 851-862.

Park JK, Liu X, Strauss TJ, McKearin DM, Liu Q. 2007. The miRNA pathway intrinsically controls self-renewal of Drosophila germline stem cells. Curr Biol 17: 533-538.

Reuter M, Chuma S, Tanaka T, Franz T, Stark A, Pillai RS. 2009. Loss of the Mili-interacting Tudor domaincontaining protein-1 activates transposons and alters the Mili-associated small RNA profile. Nat Struct Mol Biol 16: 639-646.

Ro S, Park C, Song R, Nguyen D, Jin J, Sanders KM, McCarrey JR, Yan W. 2007. Cloning and expression profiling of testis-expressed piRNA-like RNAs. RNA 13: 1693-1702.

Robine N, Lau NC, Balla S, Jin Z, Okamura K, KuramochiMiyagawa S, Blower MD, Lai EC. 2009. A broadly conserved pathway generates $3^{\prime} \mathrm{UTR}$-directed primary piRNAs. Curr Biol 19: 2066-2076.

Ruby JG, Jan CH, Bartel DP. 2007. Intronic microRNA precursors that bypass Drosha processing. Nature 448: $83-86$.

Ruby JG, Jan C, Player C, Axtell MJ, Lee W, Nusbaum C, Ge H, Bartel DP. 2006. Large-scale sequencing reveals 21U-RNAs and additional microRNAs and endogenous siRNAs in C. elegans. Cell 127: 1193-1207.

Saito K, Inagaki S, Mituyama T, Kawamura Y, Ono Y, Sakota E, Kotani H, Asai K, Siomi H, Siomi MC. 2009. A regulatory circuit for piwi by the large Maf gene traffic jam in Drosophila. Nature 461: 1296-1299.

Sarot E, Payen-Groschene G, Bucheton A, Pelisson A. 2004. Evidence for a piwi-dependent RNA silencing of the gypsy endogenous retrovirus by the Drosophila melanogaster flamenco gene. Genetics 166: 1313-1321.

Sassone-Corsi P. 2000. CREM: A master-switch regulating the balance between differentiation and apoptosis in male germ cells. Mol Reprod Dev 56: 228-229.

Schwarz DS, Hutvagner G, Du T, Xu Z, Aronin N, Zamore PD. 2003. Asymmetry in the assembly of the RNAi enzyme complex. Cell 115: 199-208.

Shoji M, Tanaka T, Hosokawa M, Reuter M, Stark A, Kato Y, Kondoh G, Okawa K, Chujo T, Suzuki T, et al. 2009. The TDRD9-MIWI2 complex is essential for piRNAmediated retrotransposon silencing in the mouse male germline. Dev Cell 17: 775-787.

Smulders-Srinivasan TK, Lin H. 2003. Screens for piwi suppressors in Drosophila identify dosage-dependent regulators of germline stem cell division. Genetics 165: 1971-1991.

Song JJ, Smith SK, Hannon GJ, Joshua-Tor L. 2004. Crystal structure of Argonaute and its implications for RISC slicer activity. Science 305: 1434-1437.

Soper SF, van der Heijden GW, Hardiman TC, Goodheart M, Martin SL, de Boer P, Bortvin A. 2008. Mouse Maelstrom, a component of nuage, is essential for 
J.P. Saxe and H. Lin

spermatogenesis and transposon repression in meiosis. Dev Cell 15: 285-297.

Suh N, Baehner L, Moltzahn F, Melton C, Shenoy A, Chen J Blelloch R. 2010. MicroRNA function is globally suppressed in mouse oocytes and early embryos. Curr Biol 20: $271-277$.

Szakmary A, Cox DN, Wang Z, Lin H. 2005. Regulatory relationship among piwi, pumilio, and bag-of-marbles in Drosophila germline stem cell self-renewal and differentiation. Curr Biol 15: 171-178.

Tam OH, Aravin AA, Stein P, Girard A, Murchison EP, Cheloufi S, Hodges E, Anger M, Sachidanandam R, Schultz RM, et al. 2008. Pseudogene-derived small interfering RNAs regulate gene expression in mouse oocytes. Nature 453: $534-538$.

Thomson T, Lin H. 2009. The biogenesis and function of PIWI proteins and piRNAs: Progress and prospect. Ann Rev Cell Dev Biol 25: 355-376.

Tuschl T, Zamore PD, Lehmann R, Bartel DP, Sharp PA. 1999. Targeted mRNA degradation by double-stranded RNA in vitro. Genes Dev 13: 3191-3197.

Unhavaithaya Y, Hao Y, Beyret E, Yin H, KuramochiMiyagawa S, Nakano T, Lin H. 2009. MILI, a PIWI-interacting RNA-binding protein, is required for germ line stem cell self-renewal and appears to positively regulate translation. J Biol Chem 284: 6507-6519.

Vagin VV, Sigova A, Li C, Seitz H, Gvozdev V, Zamore PD. 2006. A distinct small RNA pathway silences selfish genetic elements in the germline. Science 313: 320-324.

Vagin VV, Wohlschlegel J, Qu J, Jonsson Z, Huang X, Chuma S, Girard A, Sachidanandam R, Hannon GJ, Aravin AA. 2009. Proteomic analysis of murine Piwi proteins reveals a role for arginine methylation in specifying interaction with Tudor family members. Genes Dev 23: 1749-1762.

Vasileva A, Tiedau D, Firooznia A, Muller-Reichert T, Jessberger R. 2009. Tdrd6 is required for spermiogenesis, chromatoid body architecture, and regulation of miRNA expression. Curr Biol 19: 630-639.

Vermaak D, Henikoff S, Malik HS. 2005. Positive selection drives the evolution of rhino, a member of the heterochromatin protein 1 family in Drosophila. PLoS Genet 1: 96-108.

Volpe AM, Horowitz H, Grafer CM, Jackson SM, Berg CA. 2001. Drosophila rhino encodes a female-specific chromodomain protein that affects chromosome structure and egg polarity. Genetics 159: 1117-1134.

Voronina E, Seydoux G, Sassone-Corsi P, Nagamori I. 2011. RNA granules in germ cells. Cold Spring Harb Perspect Biol doi:10.1101/cshperspect.a002774.

Wang G, Reinke V. 2008. A C. elegans Piwi, PRG-1, regulates 21U-RNAs during spermatogenesis. Curr Biol 18: $861-867$.

Wang Y, Juranek S, Li H, Sheng G, Tuschl T, Patel DJ. 2008. Structure of an argonaute silencing complex with a seedcontaining guide DNA and target RNA duplex. Nature 456: $921-926$.

Wang J, Saxe JP, Tanaka T, Chuma S, Lin H. 2009. Mili interacts with Tudor domain-containing protein 1 in regulating spermatogenesis. Curr Biol 19: 640-644.

Watanabe T, Takeda A, Tsukiyama T, Mise K, Okuno T, Sasaki H, Minami N, Imai H. 2006. Identification and characterization of two novel classes of small RNAs in the mouse germline: Retrotransposon-derived siRNAs in oocytes and germline small RNAs in testes. Genes Dev 20: $1732-1743$.

Watanabe T, Totoki Y, Toyoda A, Kaneda M, KuramochiMiyagawa S, Obata Y, Chiba H, Kohara Y, Kono T, Nakano T, et al. 2008. Endogenous siRNAs from naturally formed dsRNAs regulate transcripts in mouse oocytes. Nature 453: 539-543.

Yang Y, Xu S, Xia L, Wang J, Wen S, Jin P, Chen D. 2009. The bantam microRNA is associated with Drosophila fragile $\mathrm{X}$ mental retardation protein and regulates the fate of germline stem cells. PLoS Genet 5: e1000444.

Yin H, Lin H. 2007. An epigenetic activation role of Piwi and a Piwi-associated piRNA in Drosophila melanogaster. Nature 450: 304-308.

Zamore PD, Tuschl T, Sharp PA, Bartel DP. 2000. RNAi: double-stranded RNA directs the ATP-dependent cleavage of mRNA at 21 to 23 nucleotide intervals. Cell 101: $25-33$. 


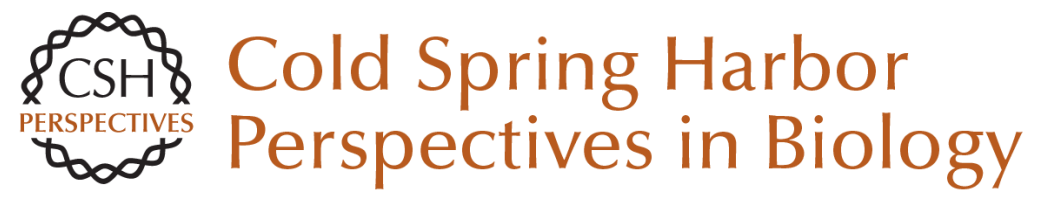

\section{Small Noncoding RNAs in the Germline}

Jonathan P. Saxe and Haifan Lin

Cold Spring Harb Perspect Biol 2011; doi: 10.1101/cshperspect.a002717 originally published online June 13, 2011

\section{Subject Collection Germ Cells}

RNA Granules in Germ Cells Ekaterina Voronina, Geraldine Seydoux, Paolo Sassone-Corsi, et al.

Function of the Sex Chromosomes in Mammalian Fertility Edith Heard and James Turner

Small Noncoding RNAs in the Germline Jonathan P. Saxe and Haifan Lin

Mammalian Genomic Imprinting Marisa S. Bartolomei and Anne C. Ferguson-Smith

Molecular Regulation of the Mitosis/Meiosis Decision in Multicellular Organisms Judith Kimble

Selection in the Rapid Evolution of Gamete Recognition Proteins in Marine Invertebrates Victor D. Vacquier and Willie J. Swanson
Developmental Control of Oocyte Maturation and Egg Activation in Metazoan Models Jessica R. Von Stetina and Terry L. Orr-Weaver

Translational Control in Oocyte Development Joel D. Richter and Paul Lasko

Unique Aspects of Transcription Regulation in Male Germ Cells Helen White-Cooper and Irwin Davidson

Germ Cell Intercellular Bridges Michael P. Greenbaum, Tokuko Iwamori, Gregory M. Buchold, et al.

Germline Stem Cells Allan Spradling, Margaret T. Fuller, Robert E. Braun, et al.

Nuclear Transfer to Eggs and Oocytes J. B. Gurdon and lan Wilmut

For additional articles in this collection, see http://cshperspectives.cshlp.org/cgi/collection/

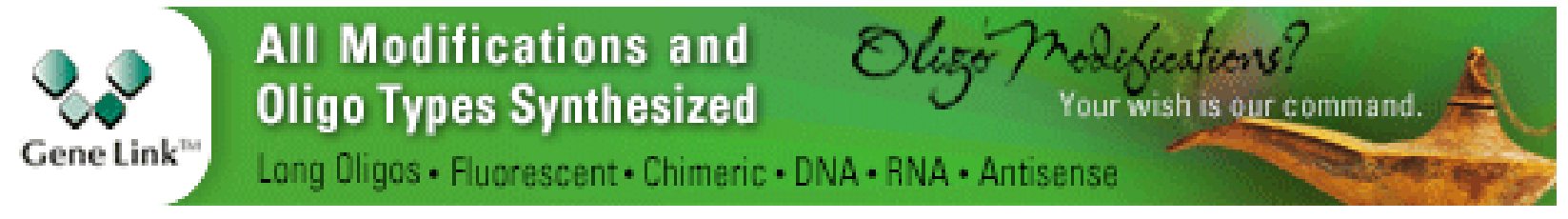

Copyright @ 2011 Cold Spring Harbor Laboratory Press; all rights reserved 